\title{
EFFECT OF DIMETHYL SULFOXIDE WET BONDING TECHNIQUE ON THE DURABILITY OF RESIN-DENTIN BOND OF AN ETCH-AND RINSE ADHESIVE SYSTEM UNDER IN-VIVO SIMULATING CONDITIONS
}

\author{
Shaymaa M. Nagi *
}

\begin{abstract}
Purpose: This study assessed the influence of new dimethyl sulfoxide (DMSO) containing pretreatments on the aged resin-dentin micro-tensile bond strength ( $\mu$ TBS) of a two-step etch-and rinse adhesive system.

Methods: Occlusal enamel of forty-eight sound molar teeth were ground to expose mid-coronal dentin. Prepared specimens were restored with Adper ${ }^{\mathrm{TM}}$ Single Bond2 (SB2) adhesive systems. Prior to the adhesive system application, specimens were randomly assigned into three groups according to dentin pretreatment [no treatment (control group), ethanol wet-bonding (EtOH), or 50 vol\% DMSO dissolved in ethanol (DMSO/EtOH)]. Resin composite block was build-up for each specimen. Specimens were stored under simulated IPP $20 \mathrm{mmHg}$, immersed in artificial saliva at $37{ }^{\circ} \mathrm{C}$ for either $24 \mathrm{~h}$ or $6 \mathrm{~m}$. Specimens were sectioned into sticks of $1 \mathrm{~mm}^{2}$ for $\mu$ TBS testing using a universal testing machine. Mode of failure was analyzed using a scanning electron microscope. Three extra sticks from each subgroup were prepared and assessed for the amount of silver nitrate penetration (wt\%) using energy dispersive analytical x-ray (EDAX). Data were statistically analyzed by Two-way ANOVA of Variance.
\end{abstract}

Results: (DMSO/EtOH) group revealed the highest statistically significant mean bond strength and the least silver nitrate penetration compared to the (control) and (EtOH) groups at $24 \mathrm{~h}$ and $6 \mathrm{~m}$. Adhesive failures was most predominant for control group at $24 \mathrm{~h}$, with increased percentage of mixed failure for EtOH and DMSO/EtOH groups at $24 \mathrm{~h}$ and $6 \mathrm{~m}$.

Conclusions: DMSO/EtOH dentin pretreatment improved the immediate and delayed resindentin bond.

Clinical significance: DMSO-bonding protocols are less technique sensitive, and simpler to apply clinically in comparison to ethanol-wet bonding due to the obviously fewer steps.

KEYWORDS: Etch-and-rinse, Dentin, Micro-tensile bond strength, Ethanol-wet bonding, Dimethyl sulfoxide

\footnotetext{
* Department of Restorative and Dental Materials, Oral and Dental Research Division, National Research Centre, Egypt
} 


\section{INTRODUCTION}

Despite the continuous improvements and advances in dental materials, early bond strength decline remains one of the complications affecting adhesive restorations. A unique form of tissue engineering is formed during bonding to dentin; where resin adhesive infiltrate into the demineralized collagen network forming hybrid layers that link resin composites to the underneath dentin. Hybrid layers are often considered the weakest points in resin-dentin interfaces. ${ }^{1,2}$ Incomplete resin infiltration into the demineralized collagen is more characteristic with the etch-and-rinse adhesion protocol., ${ }^{2,3}$ The presence of exposed collagen network between the mineralized dentin and the hybrid layer is more susceptible to creep ${ }^{1}$ and cyclic fatigue rupture ${ }^{2}$ under functioning. Moreover, these resin-sparse collagen fibrils are also loaded with water, which contributes in the hydrolysis of collagen by collagenolytic enzymes and resin matrices by esterases. ${ }^{3}$

Thus, to increase the durability of the hybrid layer, it is essential to preserve the coverage of the demineralized collagen fibrils with a well-constructed polymer network. ${ }^{4,5}$ Several bonding techniques have been proposed to improve the durability of the hybrid layers, but only few of them could be applied clinically. The ethanol wet- bonding technique is one of the most successful approaches recommended following the etch-rinse bonding ${ }^{6}$ to improve hybrid layer formation in vitro. Nevertheless, due to the time needed for successive ethanol applications for adequate dentin dehydration ${ }^{7,8}$, it is considered clinically unpractical

Lately, dimethyl sulfoxide (DMSO) [(CH3)2SO] has utilized in adhesive dentistry as a new potential solvent exhibiting many properties that may improve resin-dentin bonding. ${ }^{9-10}$ DMSO is a powerful organic solvent able to dissolve polar and non-polar compounds. ${ }^{3}$ It is considered to be one of the best penetration enhancers utilized in medical purposes due to its capability of infiltrating biological tissues. ${ }^{11}$
Thus, the current study aimed to assess the influence of pretreatment of ethanol and DMSO on immediate and aged dentin bond strength and nanoleakage of a two-steps etch-and-rinse adhesive system under in vivo simulating conditions (in terms of intra-pulpal pressure and immersion in artificial saliva at $37{ }^{\circ} \mathrm{C}$ ). The current study hypothesis was that the application of ethanol or DMSO before hybridization will not affect the aged bond strength and nanoleakage of the two-steps etch-and rinse adhesive systems to dentin.

\section{MATERIALS AND METHODS}

\section{Adhesive systems tested in the current study}

One adhesive system was tested in the current study: Adper ${ }^{\mathrm{TM}}$ Single Bond 2 (Two-step etch-andrinse adhesive system). The adhesive system was used with Filtek ${ }^{\mathrm{TM}}$ Z350 (light cured nano-hybrid resin composite). Materials compositions and manufacturers are presented in Table 1.

\section{Teeth selection and study Design}

Forty-eight recently extracted sound human third molars from 18-28 years old patients scheduled for extraction were collected from the National Research Centre outpatient clinic. Teeth were then stored in phosphate buffer solution $(\mathrm{g} / \mathrm{L})$ : $[(\mathrm{Na} 2 \mathrm{H}-$ PO4 (0.578), KH2PO4 (0.353) dissolved in distilled water containing $0.02 \%$ sodium azide] adjusted at $\mathrm{pH}=7$, and stored at $4{ }^{\circ} \mathrm{C}$ for a maximum periods of one month before being used. ${ }^{12}$ Teeth were randomly divided into three main groups $(n=16$ teeth) according to dentin pretreatment: Group I: no treatment (control group), Group II: ethanol wet-bonding (EtOH); Group III: 50 vol\% DMSO (Dimethyl Sulfoxide, Sigma-Aldrich, St Louis, MO, USA) dissolved in ethanol (Sigma-Aldrich) (DMSO/EtOH). Each group was further divided into two subgroups ( $\mathrm{n}=8$ teeth) according to the storage time: $24 \mathrm{~h}$ and $6 \mathrm{~m}$ under intrapulpal pressure immersed in artificial saliva. 
TABLE (1): Material names, composition, and manufacturers.

\begin{tabular}{|c|l|c|}
\hline Materials & \multicolumn{1}{|c|}{ Composition } & \multicolumn{1}{|c|}{ Manufacturer } \\
\hline $\begin{array}{c}\text { Adper }{ }^{\text {TM }} \text { Single Bond 2 } \\
\text { (Two -step etch- and -rinse } \\
\text { adhesive system) }\end{array}$ & $\begin{array}{l}\text { Etchant: 37\% phosphoric acid by weight. pH=0.6. Fumed silica and } \\
\text { a water soluble surfactant. } \\
\text { Adhesive: Bis-GMA, HEMA, dimethacrylates, ethanol,water, and a } \\
\text { methacrylate functional copolymer of polyacrylic and polyitaconic } \\
\text { acids. 10\% of 5 nanometer-diameter spherical silica particles by }\end{array}$ & $\begin{array}{c}\text { St. Paul, MN, USA } \\
\text { products. }\end{array}$ \\
\hline $\begin{array}{c}\text { Filtek }{ }^{\text {TM }} \mathbf{Z 3 5 0} \text { PH= 4.3. } \\
\text { (Light cured nano- hybrid } \\
\text { resin composite) }\end{array}$ & $\begin{array}{l}\text { Bis-GMA, BisEMA, UDMA+ small amount of TEGDMA, fillers: } \\
\text { Zirconia/Silica cluster filler (0.6-1.4) microns, nonagglomerated/ }\end{array}$ & $\begin{array}{c}\text { 3M ESPE Dental } \\
\text { products. St. Paul, MN, } \\
\text { USA }\end{array}$ \\
\hline
\end{tabular}

HEMA=2-hydroxyethyl methacrylate, Bis-GMA=Bis-Phenol-A glycidyl-methacrylate, UDMA=Urethane dimethacrylate, TEGDMA= Triethylene glycol dimethacrylate, BisEMA= Ethoxylated bisphenol A dimethacrylate

\section{Specimens preparation:}

Roots of all teeth were cut off $2 \mathrm{~mm}$ gingival to cemento- enamel junction. Then the pulp tissue was carefully re- moved with excavator (Dentsply/ Maillefer, Ballaigues, Switzerland) avoiding contact with the walls of the pulp chamber. Occlusal enamel was then ground to expose mid-coronal dentin. The height of the remaining dentin available for bonding was measured using precise caliper. Only crown segments with a remaining dentin thickness of $2 \mathrm{~mm}$ were used in the current study. ${ }^{13}$

The exposed dentin surfaces were further polished on wet 600 -grit silicon-carbide paper for 60 s to standardize the smear layer. ${ }^{13,14}$ Prepared crown segments were then centrally glued to a teflon plate (150mm diameter x $1 \mathrm{~mm}$ thickness), then a butterfly stainless steel needle gauge 19 (Shanchuan Medical Instruments.Co.ltd, Zibo, China) was inserted and tightly fit to a central hole at the center of the Teflon plate. Centered crown and the butterfly needle were embedded in chemically cured polyester resin (Polyester resin \#2121, Hsein,Taiwan) till $1 \mathrm{~mm}$ gingival to the CEJ. All specimens were connected to the intrapulpal pressure assembly adjusted at $20 \mathrm{mmHg}$ pressure for $24 \mathrm{~h}$ before the restorative procedures to simulate the intraoral environmental condition and to keep the teeth wet before bonding. ${ }^{13,15}$

\section{Restorative procedure}

During restorative procedures the intrapulpal pressure was reduced to $0-5 \mathrm{mmHg}$ simulating the intrapulpal pressure after taking local anesthesia with vasoconstrictor. ${ }^{13,16}$

Dentin surfaces were initially etched for $15 \mathrm{~s}$ with $\mathrm{H}_{3} \mathrm{PO}_{4} 37 \mathrm{wt} \%$ and rinsed for $15 \mathrm{~s}$. The control group was conventionally wet bonded following manufacturer's instructions. After rinsing, dentin surfaces were blot dried with sterile cotton. In experimental groups, dentin was treated with DMSOcontaining solutions or followed the ethanol-wet bonding technique. For the ethanol-wet bonding, ${ }^{17,18}$ etched dentin surfaces were dehydrated with a series of increasing ethanol concentrations $(50 \%$, $70 \%, 80 \%, 95 \%$ and $3 \times 100 \%, 30 \mathrm{~s}$ each; i.e. $3 \mathrm{~min}$ $30 \mathrm{~s}$ in total). During this procedure, dentin surfaces were kept fully immersed in the ethanol solutions to avoid collapse of demineralized collagen. The $50 \%$ DMSO (v/v) solutions were prepared by mixing equal volumes of DMSO in ethanol. $50 \mu \mathrm{L}$ of DMSO/EtOH solution ${ }^{10,19}$ were applied on the etched dentin surfaces, left undisturbed for $60 \mathrm{~s}$ and blot dried with sterile cotton Dentin surfaces presented no visible superficial moisture before bonding. 
Adper ${ }^{\mathrm{TM}}$ Single Bond 2 was applied according to the manufacturer instructions. It was applied in two to three consecutive coats with gentle agitation for $15 \mathrm{~s}$ using a fully saturated applicator. Gently air thinned for $5 \mathrm{~s}$ with oil-free air to evaporate solvents, then light cured for $10 \mathrm{~s}$ using light curing unit (Demetron LC, Kerr) at intensity $600 \mathrm{~W} / \mathrm{cm}^{2}$.

After the application of the adhesive systems, Filtek Z350 resin composite blocks were build up on the bonded specimens. Filtek Z350 was applied in two increments with light curing of each increment for 20s according to the manufacturer's instructions. Restored teeth were aged either for $24 \mathrm{~h}$ or $6 \mathrm{~m}$ under simulated intrapulpal pressure adjusted to $20 \mathrm{mmHg}$, immersed in artificial saliva at $37^{\circ} \mathrm{C}$. Artificial saliva was composed of (mmol/L): $\mathrm{CaCl}_{2}$ (0.7), $\mathrm{MgCl}_{2}(0.6), \mathrm{H}_{2} \mathrm{O}(0.2), \mathrm{KH}_{2} \mathrm{PO}_{4}(4.0), \mathrm{KCl}$ (30), $\mathrm{NaN}_{3}$ (0.3), and HEPES buffer (20). Sodium azide was included to avoid bacterial growth. ${ }^{20}$, 21 This was proved through the preservation of the clear color of artificial saliva during the study period. ${ }^{21}$

\section{Testing procedure}

\section{Microtensile bond strength ( $\mu$ TBS) testing}

All the restored teeth were sectioned into multiple sticks, of cross-sectional surface area of approximately $(1 \pm 0.05) \mathrm{mm}^{2}$. The sectioning was performed using low speed diamond disc (MTI corporation, USA) of $0.5 \mathrm{~mm}$ thickness. The resin specimen blocks were sectioned vertically into a number of slabs of approximately $(1 \pm 0.05)$ $\mathrm{mm}$ thickness. Then by rotating the specimen 90 degrees, sectioning of the specimen was completed lengthwise to obtain multiple beam-shaped sticks, each of cross-sectional surface area of approximately $(1 \pm 0.05) \mathrm{mm}^{2}$. A precise caliber (Tresna Measuring Instrument, TDS-150, Germany) was used to check the cross-sectional area and the length of the specimens. For standardization, only sticks of the same cross-sectional area, and remaining dentin thicknesses were included in the study. Twenty sticks from each subgroup were selected (total of 120 sticks from six subgroups). All stick specimens were stored in distilled water for $24 \mathrm{hr}$ until being tested. Each stick was fixed to the microtensile bond strength attachment with a cyanoacrylate adhesive (Rocket Heavy, Dental ventures of America, , CA, USA) and stressed in tension using universal Lloyd testing machine (Lloyd instruments Ltd, an Ametek company, UK) travelling at a cross-head speed of $0.5 \mathrm{~mm} / \mathrm{min}$ until failure. Microtensile bond strength (MPa) values were determined by computing the ratio of maximum load $(\mathrm{N})$ by the bonded surface area in $\mathrm{mm}^{2}$.

\section{Failure mode analysis}

Both surfaces of fractured resin-dentin beams were mounted on an aluminum stub, gold sputter coated and observed with an environmental scanning electron microscope (ESEM) (FEI Quanta 200 ESEM, France) to determine fracture patterns. The fracture modes were classified as ${ }^{22}$ : cohesive (failure exclusive within dentin or resin composite); adhesive failure (failure at resin/dentin interface); and mixed failure (failure at resin/dentin interface with cohesive failure of the neighboring substrates).

\section{Nanoleakage measurement}

Ammoniacal silver nitrate solution $(\mathrm{PH}=9.5)$ was prepared by dissolution of 25 grams of silver nitrate crystals (Sigma- Ald rich st. Louis, USA) in $25 \mathrm{ml}$ of distilled water. Concentration (28\%) ammonium hydroxide (Sigma- Ald rich st. Louis, USA) was used to titrate the black solution until it became clear, as ammonium ions complexes the silver into diamine silver ions. This solution was diluted to $50 \mathrm{ml}$ with distilled water, yielding a 50 wt $\%$ solution. ${ }^{23}$

Extra 3 sticks were selected from each subgroup for detection of the amount of silver nitrate penetration within the bonded interface. The sticks were coated with two layers of acid 
resistant varnish, except for a $1 \mathrm{~mm}$ width around the adhesive layer. The second layer of the acid resistant varnish was applied after hardening of the first layer. Specimens were immersed in a prepared $50 \%$ ammoniacal silver nitrate $(\mathrm{pH}=9.5)$ solution in complete darkness for $24 \mathrm{~h}$. Specimens were then thoroughly rinsed in distilled water and immersed in a photo-developer solution (Kodak dental x-ray developer, 506 0686; France) for 8 hours under a fluorescent light in order to reduce the silver ions to metallic silver. ${ }^{24}$ After removal from the developing solution, the specimens were placed in running water for 5 minutes, and then polished using hand pressure on stationary wet silicon carbide abrasive papers ( $\mathrm{SiC}$ grinding papers, eacowat, Frence) of 800-, 1000-, 2000 grit.

The amount of silver nitrate penetration (Wt\%) were analyzed using the EDAX (energy dispersive analytical $x$-ray). The amount of silver nitrate within the adhesive layer, hybrid layer and the resin tags, in each specimen was measured in an area $(149 \mu \mathrm{mx} 149 \mu \mathrm{m})$ at $2000 \mathrm{X}$ magnification directly on environmental scanning electron microscope (ESEM) (FEI Quanta 200 ESEM, France) monitor at 3 regions within three different sticks in each subgroup. The mean of the three regions was calculated. The silver nitrate uptake was expressed as a weight percentage of the total area evaluated.

\section{Statistical analysis}

Mean and standard deviation values were calculated for each group in each test. Data were explored for normality using Kolmogorov-Smirnov and Shapiro-Wilk tests and the data showed parametric (normal) distribution. One-way ANOVA followed by Tukey post hoc test was used to compare between more than two groups in non-related samples. Independent sample t-test was used to compare between two groups in non-related samples. Two-way ANOVA was used to test the effect of interaction between different variables. The significance level was set at $\mathrm{P} \leq 0.05$. Statistical analysis was performed with IBM ${ }^{\circledR}$ SPSS $®$ Statistics Version 20 for Windows.

\section{RESULTS}

\section{Microtensile bond strength results}

Two-way ANOVA analysis for the effect of different variables on the microtensile bond strength showed that the ageing time had a statistically significant effect $(p=<0.001)$. Also, dentin pretreatment type had a statistically significant outcome $(p=0.014)$. The interaction between the two variables had no statistically significant effect at $\mathrm{p}=0.975$.

Mean and standard deviation (SD) for the microtensile bond strength (MPa) for groups were presented in Table 2. Comparing each dentin pretreatment protocol at $24 \mathrm{~h}$ aging period, (DMSO/EtOH) group revealed the highest statistically significant mean bond strength compared to the (control) and $(\mathrm{EtOH})$ groups. No significant statistical difference was found between (EtOH) and (control) groups. On the other hand, at $6 \mathrm{~m}$ aging period, the results showed that a statistically significant difference was revealed between (control), (EtOH) and (DMSO/ $\mathrm{EtOH})$ groups. (DMSO/EtOH) group revealed the highest statistically significant mean bond strength followed by $(\mathrm{EtOH})$ then (control) group.

Regarding comparing between results of $24 \mathrm{~h}$ and $6 \mathrm{~m}$ with each tested dentin pretreatment group (Table 2), 24h showed higher statistically significant difference mean bond strength compared to the $6 \mathrm{~m}$ results in (control) group. There was also no statistically significant difference in results of $24 \mathrm{~h}$ and $6 \mathrm{~m}$ in $(\mathrm{EtOH})$ and $(\mathrm{DMSO} / \mathrm{EtOH})$ groups.

\section{Mode of failure results}

Figure 1 showed percentage of mode of failure for all groups. Failure mode analysis showed that adhesive failures was the most predominantly failure mode for control group at $24 \mathrm{~h}$, with increased 
percentage of mixed failure for groups treated with $\mathrm{EtOH}$ and $\mathrm{DMSO} / \mathrm{EtOH}$ at both $24 \mathrm{~h}$ and $6 \mathrm{~m}$ aging periods.

TABLE (2): The mean, standard deviation (SD) values of Micro-tensile bond strength (MPa) of different groups

\begin{tabular}{|c|c|c|c|c|c|}
\hline \multirow{2}{*}{ Variables } & \multicolumn{4}{|c|}{ Microtensile bond strength (MPa) } \\
\cline { 2 - 5 } & \multicolumn{2}{|c|}{$24 \mathrm{~h}$} & \multicolumn{2}{|c|}{$6 \mathrm{~m}$} & \multirow{2}{*}{ p-value } \\
\cline { 2 - 6 } & Mean & SD & Mean & SD & \\
\hline $\begin{array}{c}\text { No treatment } \\
\text { (Control) }\end{array}$ & $39.47^{\text {aA }}$ & 1.13 & 28.22 bA & 2.58 & $<0.001^{*}$ \\
\hline EtOH & $41.50^{\text {aA }}$ & 4.20 & 39.43 aв & 3.53 & $0.216 \mathrm{~ns}$ \\
\hline DMSO/EtOH & $47.20^{\text {aв }}$ & 2.86 & $45.76^{\text {ac }}$ & 4.19 & $0.114 \mathrm{~ns}$ \\
\hline p-value & $0.010^{*}$ & $0.011^{*}$ & \\
\hline
\end{tabular}

Different upper-case letters in the same column indicating statistically significant difference

Different lower-case letters in the same raw indicating statistically significant difference

*; significant $(p<0.05) \quad n s ;$ non-significant $(p>0.05)$

\section{Results of silver nitrate penetration wt $\%$}

Two-way ANOVA analysis for the effect of different variables on silver nitrate penetration (wt\%) showed that the ageing time had a statistically significant effect $(p=<0.001)$. Also, dentin pretreatment type had a statistically significant

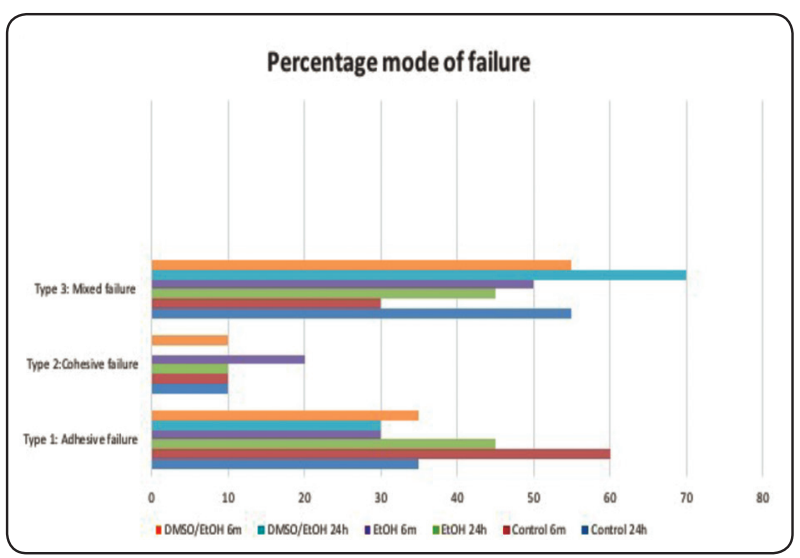

Fig. (1): Percentage mode of failure of different groups outcome $(\mathrm{p}=0.018)$. The interaction between the two variables had no statistically significant effect at $\mathrm{p}=0.5451$.

Mean and standard deviation (SD) of silver nitrate penetration wt $\%$ for different groups were presented in Table 3. Comparing each dentin pretreatment protocol at $24 \mathrm{~h}$ aging period, no significant statistical difference was found between the tested groups. On the other hand, at $6 \mathrm{~m}$ aging period, results showed (Control) group revealed the highest statistically significant mean silver nitrate penetration wt $\%$ followed by $(\mathrm{EtOH})$, then (DMSO/EtOH) groups.

Regarding comparing between results of $24 \mathrm{~h}$ and $6 \mathrm{~m}$ with each tested dentin pretreatment group (Table 3), 6m showed higher statistically significant mean silver nitrate penetration wt $\%$ compared to $24 \mathrm{~h}$ results in (control) group. No statistically significant difference in results of $24 \mathrm{~h}$ and $6 \mathrm{~m}$ in $(\mathrm{EtOH})$ and (DMSO/EtOH) groups was found.

TABLE (3): The mean, standard deviation (SD) values of silver nitrate penetration wt $\%$ of different groups

\begin{tabular}{|c|c|c|c|c|c|}
\hline \multirow{3}{*}{ Variables } & \multicolumn{5}{|c|}{ Silver nitrate penetration wt $\%$} \\
\hline & \multicolumn{2}{|c|}{$24 \mathrm{~h}$} & \multicolumn{2}{|c|}{$6 \mathrm{~m}$} & \multirow{2}{*}{$\mathrm{p}$-value } \\
\hline & Mean & SD & Mean & SD & \\
\hline $\begin{array}{c}\text { No treatment } \\
(\text { Control })\end{array}$ & $3.37^{\mathrm{aA}}$ & 1.36 & $8.10^{\mathrm{bC}}$ & 1.61 & $<0.001 *$ \\
\hline $\mathrm{EtOH}$ & $2.27^{\mathrm{aA}}$ & 0.47 & $4.47^{\mathrm{aB}}$ & 1.21 & $0.184 \mathrm{~ns}$ \\
\hline DMSO/EtOH & $2.57^{\mathrm{aA}}$ & 0.85 & $2.97^{\mathrm{aA}}$ & 0.71 & $0.564 \mathrm{~ns}$ \\
\hline p-value & \multicolumn{2}{|c|}{$0.409 \mathrm{~ns}$} & \multicolumn{2}{|c|}{$0.024 *$} & \\
\hline
\end{tabular}

Different upper-case letters in the same column indicating statistically significant difference

Different lower-case letters in the same raw indicating statistically significant difference

*; significant $(p<0.05)$

ns; non-significant ( $p>0.05$ ) 


\section{DISCUSSION}

In the present study, simulation of the oral environmental conditions in term of investigating the bond durability under simulated IPP, and teeth were immersed in artificial saliva was done, in order to avoid the discrepancy in result between the in vivo and the in vitro results. Both dentin moisture content and pulpal pressure are of major importance during dentin bonding procedures. Hydrolytic degradation was predictable from the outflow of water from the dentinal tubules under pulpal pressure that might affect the durability of resin-dentin bonding. ${ }^{25,26}$

The current study results revealed that DMSO pretreatment gave higher dentin bond strengths with no significant changes over time. On the other hand, EtOH pretreatment couldn't significantly improve the $24 \mathrm{~h}$ resin-dentin bond strength. However, no significant changes showed during the aging period as previously reported..$^{18,27}$ Therefore, the null hypothesis was rejected.

Etching of dentin with phosphoric acid resulted in suspension of the collagen fibrils in water. ${ }^{17,27}$ Demineralized collagen had a soft and flexible nature making it highly vulnerable to hydrogen bonding between neighboring collagen peptides after water removal ${ }^{17}$ or when the bonding resin solvents compete with water for interpeptide hydrogen bonding. ${ }^{28}$ Dehydration state of the demineralized collagen fibrils lead to stiffening the dentin matrix in collapsed state, resulting in reducing the interfibrillar spaces width followed by reduction in monomer diffusion into the closely packed collagen fibrils network. Unfortunately, the collapsed collagen matrix could not be expanded with the methacrylate monomers. ${ }^{17}$ Thus, it seems that the ethanol-wet bonding and DMSO pretreatment played a role in the stability of the collagen matrix prior to hybridization. This was also supported by failure modes results in the current study that showed an increased percentage of mixed failure for groups treated with $\mathrm{EtOH}$ and $\mathrm{DMSO} / \mathrm{EtOH}$ at $6 \mathrm{~m}$ aging periods indicating an increase in bond strength compared to the control group which showed increased adhesive failure mode.

Ethanol-wet bonding protocol depends on chemical dehydration, where ethanol replace the remaining water in the demineralized collagen network. On the other hand, DMSO-bonding relays on the strong DMSO-water interaction. ${ }^{29}$ It reduces water cohesive forces and surface tension by breaking down water self-associative affinities and consequently enhances the adhesive wetting tendency. ${ }^{30}$

DMSO has the capability to break down the self-associative tendency of water ${ }^{29}$, this might also lessen the water molecules number that is trapped between the polymeric chains, improving the degree of postoperative polymerization. Moreover, reducing free water would diminish or eliminate the hydrolytic degradation of adhesive in the hybrid layer. ${ }^{31}$ This could explain the superiority of DMSO pretreatment in the immediate and delayed bond strength results and its lower nanoleakage tendency after the $6 \mathrm{~m}$ aging period compared to the ethanol wet bonding technique.

A recent study by Stape et al, ${ }^{22}$ confirmed the higher monomer infiltration produced by $\mathrm{DMSO},{ }^{3}$ that enabled conversion of the monomers at the deeper layer of the hybrid layer. A positive correlation between the degree of conversion and the bond strength was found with DMSO pretreatments groups. They claimed that DMSO reduces the termination frequencies in poly-methacrylate free radical polymerization developing elongated chains. ${ }^{32}$ Thus, the crosslinking between chains and reinforcement of the polymer structure took place. ${ }^{22}$

In both tested bonding scenarios, the collagen interfibrillar spaces increased by shrinking the collagen fibrils due to removal of water by ethanol ${ }^{33}$ or by modification of the collagen structure made by the action of DMSO. ${ }^{34}$ Dissociation of the collagen fiber bundles into a sparser network of apparent fibrils occurred with the application of DMSO ${ }^{35,31,36}$ 
which is not observed with ethanol pretreatment. Disruption of the hydration shell and changes in water molecules in the highly hydrated collagen molecules and fibrils lead to the DMSO induced collagen dissociation which promote the infiltration of monomer into the etched dentin matrix. ${ }^{31,37}$

In addition, both tested techniques enhance dentin wetting. ${ }^{38,30}$ When ethanol and DMSO are applied on the etched dentin surface, the contact angle decreases indicating that both of them can improve the wetting of etched dentin. ${ }^{35}$ A low contact angle denotes greater energy and enhanced contact of resin with the dentin surface and improved infiltration into the hybrid layer. ${ }^{17,33,35}$

DMSO has excellent balance between polar and surface tension properties, low surface tension, and high dielectric constant. ${ }^{39}$ All of these properties allow it to be a perfect wetting agent especially for porous surfaces.

Moreover, DMSO can hydrogen-bond to proteins ${ }^{40}$ and preclude collagen fibrils collapse during air drying. ${ }^{28}$ Advance wetting and decreased shrinkage during drying, could guarantee that the adhesive fully wets and covers the entire prepared surface. This could clarify the deeper adhesive infiltration into the exposed collagen, ${ }^{3}$ and the reduced nanoleakage results found in the current study.

The superiority of DMSO pretreated group in the immediate and delayed bond strength results and its lower nanoleakage tendency, may not only be related to its improved resin-dentin interaction as previously mentioned, but also may be due to its inhibitory effect on human gelatinases, ${ }^{19,31}$ thus preventing the hydrolytic degradation of exposed collagen in the hybrid layer. It has been confirmed that DMSO can interrupt the interactions between the gelatinase binding site and substrate, in addition to reduce the activity of human gelatinases MMP-2 and MMP-9. ${ }^{30}$ DMSO resulted in protein unfolding and thus denaturation due to its binding to enzyme's hydrophobic moieties. ${ }^{41}$
Even though EtOH dentin pretreated group presented improved delayed bond strength, and nanoleakage than the control group still it was significantly lower than the DMSO pretreated group. Ethanol wet bonding technique was considered to be technique sensitive and impractical clinically because of the time needed for successive ethanol applications for proper dentin dehydration. ${ }^{7,8}$ The amount of water in dentin was expected to be high in the current study due to aging of the restored specimens under intrapulpal pressure. This might lead to more water was left in the deeper layers of demineralized dentin collagen that was not reached by ethanol application and consequently leading to the activation of endogenous enzymes. ${ }^{42}$ Stape et al., ${ }^{22}$ assessed the mechanical stability of the collagen fibrils and its dry mass loss over time using the three-point bending test. They found reduction in elastic modulus with increase in dry mass loss of ethanol-treated collagen due to modifications in collagen structure as a result of peptide solubilization. This was explained due to the poor inhibition produced by ethanol to matrix metalloproteinases. ${ }^{43}$ In contrast to DMSO solutions that was able to preserve the mechanical properties of collagen and reduce collagen solubilization. ${ }^{22}$

\section{CONCLUSIONS}

Within the limitations of the current study it could be concluded that: DMSO/EtOH dentin pretreatment improved the immediate and delayed resin-dentin bond. DMSO-bonding protocols are less technique sensitive, and simpler to apply clinically in comparison to ethanol-wet bonding due to the obviously fewer steps.

\section{REFERENCES}

1. Zhang Z, Beitzel D, Mutluay M, Tay FR, Pashley DH,Arola D. On the durability of resin-dentin bonds: identifying the weakest links. Dent Mater 2015;31:1109-18,

2. Spencer P, Wang Y, Katz JL. Identification of collagen encapsulation at the dentin/adhesive interface. J Adhes Dent 2004;6:91-5. 
3. Stape THS, Tjäderhane L, Marques MR, Aguiar FHB, Martins LRM. Effect of dimethyl sulfoxide wet-bonding technique on hybrid layer quality and dentin bond strength. Dent Mater 2015;31:676-83.

4. Van Meerbeek B, Van Landuyt K. From Buonocore's pioneering acid-etch technique to self-adhering restoratives. A status perspective of rapidly advancing dental adhesive technology. J Adhes Dent 2020;22:7-34.

5. Breschi L, Maravic T, Cunha SR, Comba A, Cadenaro M, Tjäderhane L, et al. Dentin bonding systems: from dentin collagen structure to bond preservation and clinical applications. Dent Mater 2018;34:78-96.

6. Becker TD, Agee KA, Joyce AP, Rueggeberg FA, Borke JL, Waller JL, et al. Infiltration/evaporation-induced shrinkage of demineralized dentin by solvated model adhesives. J Biomed Mater Res B Appl Biomater 2007;80B:156-65.

7. Tay FR, Osorio E, Osorio R, Aguilera FS, Toledano M. Ethanol wet-bonding technique sensitivity assessed by AFM. J Dent Res 2010;89:1264-9.

8. Sadek FT, Mazzoni A, Breschi L, Tay FR, Braga RR. Six-month evaluation of adhesives interface created by a hydrophobic adhesive to acid-etched ethanol-wet bonded dentine with simplified dehydration protocols. J Dent 2010;38:276-83.

9. Stape THS, Tjäderhane L, Abuna G, Sinhoreti MAC, Martins LRM, Tezvergil-Mutluay A. Optimization of the etch-and-rinse technique: new perspectives to improve resin-dentin bonding and hybrid layer integrity by reducing residual water using dimethyl sulfoxide pretreatments. Dent Mater 2018;34:967-77.

10. Stape THS, Tjäderhane L, Tezvergil-Mutluay A, Yanikian CRF, Szesz AL, Loguercio AD, et al. Dentin bond optimization using the dimethyl sulfoxide-wet bonding strategy: a 2-year in vitro study. Dent Mater 2016;32:1472-81.

11. Marren, K., Dimethyl sulfoxide: an effective penetration enhancer for topical administration of NSAIDs. Phys Sportsmed, 2011; 39:75-82.

12. De Munck J, Van Landuyt K, Peumans M, Poitevin A, Lambrechts P, Braem M, et al. A critical review of the durability of adhesion to tooth tissue: methods and results. J Dent Res. 2005; 84(2):118-132.

13. Nagi SM. Durability of solvent-free one-step self-etch adhesive under simulated intrapulpal pressure. J Clin Exp Dent. 2015;7(4):e466-70.
14. El Zohairy A, Saber M, Abdalla A, Feilzer A. Efficacy of microten- sile versus microshear bond testing for evaluation of bond strength of dental adhesive systems to enamel. Dent Mater. 2010; 26:848-54.

15. Abdalla A.I, Elsayed HY. García GF. Effect of hydrostatic pulpal water pressure on microtensile bond strength of self-etch adhesives to dentin. Am J Dent. 2008; 21:233-8.

16. Sauro S, Pashley DH, Montanan M, Chersoni S, Carvaiho JI, Toledano M, et al. Effect of simulated pulpal pressure on dentin permeability and adhesion of self-etch adhesives. Dent Mater. 2007;23:705-13.

17. Pashley DH, Tay FR, Carvalho RM, Rueggeberg FA, Agee KA, Carrilho M, et al. From dry bonding to water-wet bonding to ethanol-wet bonding. A review of the interactions between dentin matrix and solvated resins using a macromodel of the hybrid layer. Am J Dent 2007;20:7-20.

18. Sadek FT, Castellan CS, Braga RR, Mai S, Tjäderhane L, Pashley DH, et al. One-year stability of resin-dentin bonds created with a hydrophobic ethanol-wet bonding technique. Dent Mater 2010;26:380-6.

19. Stape THS, Seseogullari-Dirihan R, Tjäderhane L, Abuna G, Martins LRM, Tezvergil-Mutluay A. A novel dry-bonding approach to reduce collagen degradation and optimize resin-dentin interfaces. Sci Rep 2018;8:16890.

20. Komori PC, Pashley DH, Tjaderhane L, Breschi L, Mazzoni A, de Goes MF, Wang L \& Carrilho MR. Effect of $2 \%$ chlorhexidine digluconate on the bond strength to normal versus caries affected dentiN. Operative Dentistry 2009; 34(2) 157-165.

21. Mobarak EH. Effect of Chlorhexidine Pretreatment on Bond Strength Durability of Caries-affected Dentin Over 2-Year Aging in Artificial Saliva and Under Simulated Intrapulpal Pressure Oper Dent. 2011; 36 (6): 649-660.

22. Stape THS, Mutluay MM, Tjäderhane L, Uurasjärvi E, Koistinen A,Tezvergil-Mutluay A. The pursuit of resindentin bond durability: Simultaneous enhancement of collagen structure and polymer network formation in hybrid layers. Dental Materials. 2021; 37: 1083-1095.

23. Tay FR, King NM, Chan KM, Pashley DH. How can nanoleakage occur in self-etching adhesive systems that demineralize and infiltrate simultaneously? Journal of Adhesive Dentistry 2002; 4: 255-69.

24. Hashimoto M, Fujita S, Nagano F, Ohno H \& Endo K. Ten-years degradation of resin-dentin bonds. European Journal of Oral Sciences 2010;18(4) : 404-410. 
25. Osoria R, Jatyr PP, Erhardt MCG, Osorio E, Aguilera FS, Tay FR, et al. Resistance of ten contemporary adhesives to resindentine bond degradation. J Dent. 2008; 36(2):163-169.

26. Van Landuyt SL, De Munck J, Snauwaert J, Coutinho E, Poitevin A, Yoshida Y, et al. Monomer-solvent phase separation in one-step self-etch adhesives. J Dent Res. 2005; 84(2):183-188

27. Pashley DH, Tay FR, Breschi L, Tjäderhane L, Carvalho $\mathrm{RM}$, Carrilho M, et al. State of the art etch-and-rinse adhesives. Dent Mater 2011;27:1-16.

28. Pashley DH, Agee KA, Nakajima M, Tay FR, Carvalho RM, Terada RSS, et al. Solvent-induced dimensional changes in EDTA-demineralized dentin matrix. J Biomed Mater Res 2001;56:273-81.

29. Vishnyakov A, Lyubartsev AP, Laaksonen A. Molecular dynamics simulations of dimethyl sulfoxide and dimethyl sulfoxide-water mixture. J Phys Chem A 2001;105:1702-10,

30. Mehtälä P, et al. Effect of dimethyl sulfoxide on dentin collagen. Dent Mater 2017.

31. Tjäderhane L, Mehtala P, Scaffa P, Vidal C, Paakkonen $\mathrm{V}$, Breschi L, et al. The effect of di- methyl sulfoxide (DMSO) on dentin bonding and nanoleakage of etch-andrinse adhesives. Dent Mater 2013; 29: 1055-62.

32. Gupta SN, Nandi US. Role of dimethyl sulfoxide as a solvent for vinyl polymerization. J Polym Sci A-1 Polym Chem 1970;8:1493-501.

33. Tay FR, Pashley DH, Kapur RR, Carrilho MRO, Hur YB, Garrett LV, et al. Bonding BisGMA to dentin - a proof of concept for hydrophobic dentin bonding. J Dent Res 2007;86:1034-9,

34. Zimmerley M, McClure RA, Choi B, Potma EO. Following dimethyl sulfoxide skin optical clearing dynamics with quantitative nonlinear multimodal microscopy. Appl Opt 2009;48:D79.
35. Guo J, Lei W, Yang H, Zhang Y, Zhao S, Huang C. Dimethyl Sulfoxide Wet-bonding Technique May Improve the Quality of Dentin Bonding. J Adhes Dent 2017; 19: 229-37.

36. Bui AK, McClure RA, Chang J, Stoianovici C, Hirshburg J, Yeh AT, et al. Revisiting optical clearing with dimethyl sulfoxide (DMSO). Lasers in Surgery and Medicine 2009; 41: 142-8.

37. Venkataramanan NS. Microsolvation of DMSO: density funct- ional study on the structure and polaraizabilities. International Journal of Quantum Chemistry 2012; 112: 2599-606.

38. Li F, Liu X-Y, Zhang L, Kang J-J, Chen J-H. Ethanol-wet bonding technique may enhance the bonding performance of contemporary etch-and-rinse dental adhesives. J Adhes Dent 2012;14:113-20.

39. Redón R, Vázquez-Olmos A, Mata-Zamora M, Ordó ñez- Medrano A, Rivera-Torres F, Saniger J. Contactangle studies on anodic porous alumina. J Coll Interface Sci 2005; 287: 664-70.

40. Zheng Y-A, Ornstein RL. A molecular dynamics andquantum mechanics analysis of the effect of DMSO onenzyme structure and dynamics: subtilisin. J Am Chem Soc1996; 118: 4175-80.

41. Arakawa T, Kita Y, Timasheff SN. Protein precipitation and denaturation by dimethyl sulfoxide. Biophys Chem 2007;131:62-70.

42. Ahn, J., et al., Effect of additional etching and ethanol-wet bonding on the dentin bond strength of one-step self-etch adhesives. 2015. 40(1): p. 68-74.

43. Tezvergil-Mutluay A, Agee KA, Hoshika T, Uchiyama T, Tjäderhane L, Breschi L, et al. Inhibition of MMPs by alcohols. Dent Mater 2011;27:926-33. 